\title{
MODELLING AND EXPERIMENT OF BUILDINGS THERMO-AERAULIC BEHAVIOR ACCORDING TO THE LEVEL-COMPACTNESS IN SAHARAN CLIMATE CONDITIONS
}

\author{
Sidi Mohammed El Amine BEKKOUCHE ${ }^{\mathrm{a}}$, Tayeb BENOUAZ ${ }^{\mathrm{b}}$, Maamar HAMDANI $^{\mathrm{a}}$, \\ Mohamed Kamel CHERIER ${ }^{a}$, Mohamed Rédha YAICHE ${ }^{c}$, Noceir BENAMRANE ${ }^{a}$ \\ ${ }^{a}$ Unité de Recherche Appliquée en Energies Renouvelables, URAER, \\ Centre de Développement des Energies Renouvelables, CDER, 47133, Ghardaïa, Algeria \\ ${ }^{b}$ University of Tlemcen, BP. 119, Tlemcen R.p. 13000 Algeria \\ ${ }^{c}$ Centre de Développement des Energies Renouvelables, CDER, \\ BP 62 Route de l'Observatoire, Bouzaréah, 16340, Algiers, Algeria
}

Received 20 March 2015; accepted 07 July 2016

\begin{abstract}
A large number of studies of building energy simulation neglect the humidity, or well represented, with a very simplified method. It is for this reason that we have developed a new approach to the description and modelling of multizone buildings in Saharan climate. The concept of the form factor and index compactness "quotient of external walls area and volume of the building" are two of the key elements for analyzing the building geometry. We can introduce it's as validation tools in some cases.

In this paper, governing equations of physical phenomena allow to build a model of the thermo-aeraulic behavior. The primary objective is the validation of numerical results able to determine the humidity and temperature in a multizone space. The calculated results were compared with firstly, experimental values, and secondly with simulated results using TRNSYS software. We check if the results change radically for an invariable compactness index.

The comparison shows that the found results are to some extent satisfactory. For buildings of similar thermal properties, especially, the used construction materials, the thermal insulation and thermal inertia level, orientation, etc., the result proves that temperature and specific humidity varie slightly when the compactness index is constant.
\end{abstract}

Keywords: multi-zone model, nodal method, temperature, specific humidity, wall sizes, form factor, compactness index.

\section{Introduction}

An important area of research for building thermal modeling is constructing reduced order models of inter-zone heat transfer. In 1994, a simplified thermal model for the prediction of the thermal performance of buildings is proposed by Mathews et al. Unfortunately, it has been developed using physically interpretable (debatable) assumptions. Then in 2005, a coupling between a building thermal simulation code and genetic algorithm was made to make a comparison between simulated and measured temperatures in the ground at different depth (Lauret et al. 2005). However, the effect of the choice of thermal comfort model on the building's energy use is analysed for the design of buildings with thermally activated building systems situated in a moderate climate (Sourbron, Helsen 2011). While (Goyal, Barooha 2012) mentioned in their article that there are a limited number of existing techniques for 
non-linear systems. In these works, a used method for reducing the dynamic model order of temperature and humidity in a multi-zone building is proposed.

Shape is an important factor in a low-energy building (Wang et al. 2006). In consulting the buildings geometrical aspect in the literature, it is drawn that there is not much work studying precisely the influence of the geometric shape on the temperature and specific humidity inside the building. Depecker et al. (2001), have studied the effect of design on the energy consumption of a series of buildings. The results show that the energetic consumption is reduced by improving the compactness during a very cold period

In 2009, AlAnzi et al. provide an estimation of the impact of building shape on energy efficiency of office buildings in Kuwait. The aim was to develop further research on several geometric shapes, we quote an indication: rectangular forms, L-shape, U-shape, and H-shape. In other works (Granadeiro et al. 2013), authors set out a rigorous methodology to optimize the geometric shape which will add a positive contribution to the associated design. Indeed, it is known that the spherical shape is the most compact design to ensure consistent bioclimatic design. It is by this argument that we believe and justify the choice made by Wang et al. (2006), because in this paper, the building footprint is represented by a multi-sided polygon (including hexagon) and the nearest simplest form to the sphere is that of a hexagon.

Some current building simulation programs lack the capability to properly model emerging building energy systems due to the negligence of the humidity, or well represented, with a very simplified method. Thermo-aeraulic modelling is essential for establishing overall thermal performance values and understand how different assembly designs perform under different interior and exterior climate conditions. This tool is used to evaluate the performance of a proposed architecture for a real building located in Saharan regions.

The novelty of this contribution is to couple a spreading model proposed by Rumianowski et al. in 1989, which effectively identifies the conduction and superficial exchanges with an enthalpy-known model (Roux 2000).

The adopted procedures empowered to test this proposed approach are based on three different methods. First, section 5 is entrusted to an experimental validation of two main parameters (humidity and tem- perature) of the thermo-aeraulic comfort for an office working. In the next section, we confront also temperatures with the calculated temperatures obtained by TRNSYS multizone building model. And finally, in section 8 from a geometric analysis, an evaluation of the thermo-aeraulic comfort in summer and winter periods according wall sizes will be debated. We check if the results change radically for an invariable compactness index.

\section{Enthalpy and mass balances}

Assuming that the zone $i$ is in contact with $\mathrm{N}+1$ other zone, the outdoor area is symbolized by by area $\mathrm{N}^{\circ} 0$. For the zone $i$, the enthalpy change per unit time is written by the following equation (Roux 2000):

$$
\begin{gathered}
\frac{d H(i)}{d t}=\frac{d H^{e}(i)}{d t}-\frac{d H^{\text {leav }}(i)}{d t}+ \\
Q_{i j}+P_{L}+P_{s}+C I_{L}+C I_{s} ; \\
H^{e}(i)=\sum_{n=0}^{N} Q_{\text {mas }}^{\text {trans }}(n, i)\left(T_{a l}(n) C_{a s}+r_{s}(n)\right)\left(L_{v}+C_{v} T_{a l}(n)\right) ; \\
H^{\text {leav }}(i)=\sum_{n=0}^{N} Q_{\text {mas }}^{\text {trans }}(i, n)\left(T_{a l}(i) C_{a s}+r_{s}(i)\right)\left(L_{v}+C_{v} T_{a l}(i)\right) ; \\
Q_{i j}=\sum_{j=i}^{N W(i)} S_{j} h_{c i j}\left(T_{s i j}(i)-T_{a l}(i)\right) .
\end{gathered}
$$

$Q_{i j}$ - expressions of the convective flow exchange between surfaces $j$ of walls for zone i corresponding to a temperature $T s_{i j}$ and the air mass in this zone corresponding to a temperature $T_{a l}(\mathrm{~W})$.

Expression of convective transfer coefficients due to exchange between the air and walls inner surfaces are given in Table 1.

Thermal proprieties, Prandtl and Grashof numbers are defined as function as temperature.

However, instantaneous variation in mass is a very low amount, which allows simplification of the conservation equation of air mass in zone $i$ (Roux 2000).

This equation indicates that the sum of the mass flows of dry air entering the zone $i$ is equal to the sum of the mass flows leaving the zone $i$.

$$
\begin{aligned}
& \sum_{n=0}^{N} Q_{\text {mas }}^{\text {trans }}(n, i)-Q_{\text {mas }}^{\text {trans }}(i, n)=\frac{d m_{a s}}{d t} \approx 0 \Rightarrow \\
& \sum_{n=0}^{N} Q_{\text {mas }}^{\text {trans }}(n, i)=\sum_{n=0}^{N} Q_{\text {mas }}^{\text {trans }}(i, n) .
\end{aligned}
$$

This equation allows us to simplify the writing of enthalpy balances. 
Table 1. Expression of convective transfer coefficients (Jannot 2012)

\begin{tabular}{|l|c|c|c|}
\hline \multicolumn{1}{|c|}{ Surface description } & Flow regime & Condition & Expression \\
\hline \multirow{2}{*}{ Vertical wall } & Laminar regime & $10^{4}<\mathrm{Gr} \operatorname{Pr}<10^{9}$ & $h_{\text {Conv }}=1.42(\Delta T / L)^{1 / 4}$ \\
\cline { 2 - 4 } & Turbulent regime & $\mathrm{Gr} \operatorname{Pr}>10^{9}$ & $h_{\text {Conv }}=1.31(\Delta T / L)^{1 / 3}$ \\
\hline \multirow{2}{*}{$\begin{array}{l}\text { An upper surface of an hot horizontal plate } \\
\text { or an underside surface of a cold plate }\end{array}$} & Laminar regime & $10^{4}<\mathrm{Gr} \operatorname{Pr}<10^{9}$ & $h_{\text {Conv }}=1.32(\Delta T / L)^{1 / 4}$ \\
\cline { 2 - 4 } & Turbulent regime & $\mathrm{Gr} \operatorname{Pr}>10^{9}$ & $h_{\text {Conv }}=1.52(\Delta T / L)^{1 / 3}$ \\
\hline $\begin{array}{l}\text { An underside surface of a hot plate or an upper } \\
\text { surface of an cold plate }\end{array}$ & Laminar regime & $10^{4}<\mathrm{Gr} \operatorname{Pr}<10^{9}$ & \multirow{2}{*}{$h_{\text {Conv }}=0.59(\Delta T / L)^{1 / 4}$} \\
\cline { 2 - 3 } & Turbulent regime & $\mathrm{Gr} \operatorname{Pr}>10^{9}$ & \\
\hline
\end{tabular}

An enthalpy change corresponds to the absorbed or released energy during a chemical reaction at a constant pressure and temperature (Roux 2000).

$$
\begin{aligned}
& H(i)=H_{s}(i)+H_{L}(i)= \\
& m_{a s} C_{a s} T_{a l}(i)+m_{a s} r_{s}(i)\left(L_{v}+C_{v} T_{a l}(i)\right) .
\end{aligned}
$$

The amount value given by the expression $m_{a s} C_{V}$ $T_{a l}(i)$ is very low compared to the amount expressed by $m_{a s} L_{V} r_{s}(i) ; L_{V}=2500 \mathrm{kj} / \mathrm{kg}$ and $C_{V}=1.96 \mathrm{kj} / \mathrm{kg} \mathrm{K}$.

$$
\begin{aligned}
& H_{s}(i) \approx m_{a s} C_{a s} T_{a l}(i) ; \\
& H_{L}(i) \approx m_{a s} r_{s}(i) L_{v} .
\end{aligned}
$$

Therefore, in the sensible balance, the change in enthalpy can be assimilated to the variation in temperature:

$$
\begin{gathered}
\frac{d H_{s}(i)}{d t}=\frac{d\left(m_{a s} C_{a s} T_{a l}(i)\right)}{d t}= \\
C_{a s} \frac{d m_{a s}}{d t} T_{a l}(i)+C_{a s} \frac{d T_{a l}(i)}{d t} m_{a s} ; \\
\frac{d H_{s}(i)}{d t}=\frac{d H_{s}^{e}(i)}{d t}-\frac{d H_{s}^{\text {leav }}(i)}{d t}+Q_{i j}+P_{s}+C I_{s} .
\end{gathered}
$$

The obtained agreement led us to conclude Equation (11):

$$
\begin{aligned}
& \rho_{a s} C_{a s} V(i) \frac{d T_{a l}(i)}{d t}= \\
& \sum_{i=0}^{N}\left[Q_{\text {mas }}^{\text {trans }}(i, n) C_{a s}\left(T_{a l}(n)-T_{a l}(i)\right)\right]+Q_{i j}+P_{s}+C I_{s} .
\end{aligned}
$$

The air temperatures in all zones can be deduced from Equation (11), this $n$-equations system is entirely dependent on the surfaces temperatures $T_{S i j}$ of opaque walls within the zone $i$. The ordinary differential equations system will be in direct interaction with the conduction model described in detail in the section 3 . Neglecting the term $d m_{a s} / d t$, and with using the simplified conservation equation of the dry air mass, we can lead to the following equation (Roux 2000):

$$
\frac{H_{L}(i)}{d t}=\frac{d H_{L}^{e}(i)}{d t}-\frac{d H_{L}^{\text {leav }}(i)}{d t}+P_{L}+C I_{L},
$$

knowing that

$$
m_{a s}(i)=\frac{V(i)}{v_{s}(i)} .
$$

Equation (12) will be transformed into an ordinary differential equation:

$$
\begin{aligned}
& \frac{d H_{L}(i)}{d t}=\frac{d\left(m_{a s} r_{s}(i) L v\right)}{d t}= \\
& L v \frac{d m_{a s}}{d t} r_{s}(i)+L v \frac{d r_{s}(i)}{d t} m_{a s} .
\end{aligned}
$$

The concordance between Equations (1) and (14) leads to the following equation:

$$
\begin{aligned}
& m_{a s}(i) \frac{d r_{s}(i)}{d t}= \\
& \sum_{i=0}^{N}\left[Q_{\text {mas }}^{\text {trans }}(i, n)\left(r_{s}(n)-r_{s}(i)\right)\right]+\frac{P_{L}}{L_{v}}+\frac{C I_{L}}{L_{v}} .
\end{aligned}
$$

As for the sensitive balance, a system of $N$ equations with $N$ unknowns is obtained; the main variables are the specific humidities in each zone.

\section{Transposition of the heat conduction problem}

For an opaque wall, we retain two temperatures as boundary conditions. With the unidirectionality assumption of conduction transfers, the study area is divided into a finite number of elements. The transposition of the thermal conduction problem in an electrical conduction problem is then known as thermoelectric analogy. Exploiting this analogy, nodal method leads to the establishment of an electrical network. The nodes symbolize equipotential, correspond to temperature isotherms. These isothermal elements resulting from discretization hypotheses allow a widespread description and a successful implementation of the monodimensionelle conduction. Secondly, each node is assigned an electrical capacitance, reflecting the heat 
capacity of the respective wall portion to translate the thermal inertia effect. Figure 1 is an illustrative schematic of the discretisation.

The corresponding formulas are provided by the following equation (Rumianowski et al. 1989; Mora 2003):

$$
R_{A}=\sum_{k=1}^{n_{A}} \frac{e_{k}}{\lambda_{k} S_{k}} ; \quad R_{B}=\sum_{k=n_{A}+1}^{n} \frac{e_{k}}{\lambda_{k} S_{k}} ; n=n_{A}+n_{B} .
$$

Heat capacities are determined as follows (Rumianowski et al. 1989; Mora 2003):

$$
\begin{gathered}
C_{A}=\sum_{k=1}^{n_{A}} \rho_{i} c p_{i} e_{i} S_{i}\left(1-\beta_{i}\right) ; \\
C_{B}=\sum_{j=n_{A}+1}^{n} \rho_{j} c p_{j} e_{j} S_{j} \delta_{j} ; \\
C_{M}=\sum_{k=1}^{n_{A}} \rho_{i} c p_{i} e_{i} S_{i} \beta_{i}+ \\
\sum_{j=n_{A}+1}^{n} \rho_{j} c p_{j} e_{j} S_{j}\left(1-\delta_{j}\right) ; \\
\beta_{i}=\frac{\frac{e_{i}}{2 \lambda_{i} S_{i}}+\sum_{k=1}^{i-1} \frac{e_{k}}{\lambda_{k} S_{k}}}{R_{A}} ; \\
\delta_{j}=\frac{\frac{e_{j}}{2 \lambda_{j} S_{j}}+\sum_{k=n_{A}+1}^{j-1} \frac{e_{k}}{\lambda_{k} S_{k}} .}{R_{B}} .
\end{gathered}
$$

The equivalent model which defines the temperatures balance of the isothermal surfaces is given by the system which consists of the following equations:

$$
\begin{aligned}
& C_{A} \frac{d T_{A}}{d t}=\frac{T_{M}-T_{A}}{R_{A}}+ \\
& \sum_{i=1}^{m} S F_{\text {Surf }-i} \sigma\left(T_{i}^{4}-T_{A}^{4}\right)+ \\
& S h_{\text {conv }}\left(T_{\text {air }}-T_{A}\right) ;
\end{aligned}
$$

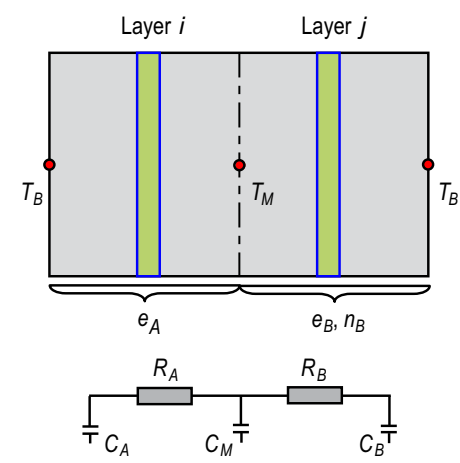

Fig. 1. Wall discretisation and conduction model (Rumianowski et al. 1989; Mora 2003)

$$
\begin{aligned}
& C_{B} \frac{d T_{B}}{d t}=\alpha S G+\frac{T_{M}-T_{B}}{R_{B}}+ \\
& \varepsilon S \frac{1-\cos \beta}{2}\left(T_{\text {Ground outside }}^{4}-T_{B}^{4}\right)+ \\
& \varepsilon S \frac{1+\cos \beta}{2}\left(T_{\text {Sky }}^{4}-T_{B}^{4}\right)+S h_{\text {convamb }}\left(T_{a m b}-T_{B}\right) \\
& C_{M} \frac{d T_{M}}{d t}=-\frac{T_{M}-T_{A}}{R_{A}}-\frac{T_{M}-T_{B}}{R_{B}}
\end{aligned}
$$

In the multizone-zone model a given building is made up with a certain number of rooms, walls, doors and also glass windows. The physical model of the building is obtained by assembling thermal models of each element, ie Equations (11), (15), (22), (23), and (24).

\section{Accurate prediction of the form factor}

The variation in the geometric shape of the building causes a modification of the surface exchange with indoor air (heat exchange by convection) and with other surfaces surrounding the same area (radiation heat exchange). This latter mode depends on exchange surfaces of the various opaque walls, walls temperatures and the form factor $\left(F_{\text {surf }-i}\right)$ between receiving and emissive surface. From this factor, we can describe the arrangement of a surface relative to the other surface. Therefore, the variation in wall surface evokes a radical change in this factor which is purely geometric. Indeed, the evaluation of form factor is numerically complex. Researchers prefer to use nomograms when they exist, instead of seeking analytical solutions. In this contribution, we will use the analytical solutions which have many advantages in particular accuracy. In summary, we can conclude that when changing walls properties, automatically there will be radical changes in sensible and latent balances since the heat flux exchanged by conduction, convection and radiation will also be changed.

First, we are interested in calculating the form factor between two plane-parallel rectangular surfaces, of any dimensions, centered or/and not centered. In this regard, it provides a descriptive diagram of the geometric problem in Figure 2.

Assuming that:

$$
\begin{aligned}
& M M^{\prime}=r, \quad O O^{\prime \prime}=\rho_{0}\left(a_{0}, b_{0}, 0\right) ; \\
& O^{\prime} M^{\prime}=\rho^{\prime}\left(X^{\prime}, Y^{\prime}, 0\right) ; \\
& r^{2}=\left(X-X^{\prime}-a_{0}\right)^{2}+\left(Y-Y^{\prime}-b_{0}\right)^{2}+d^{2} ; \\
& O^{\prime} O^{\prime \prime}=d ; \\
& \cos \theta=\cos \theta^{\prime}=d / r .
\end{aligned}
$$




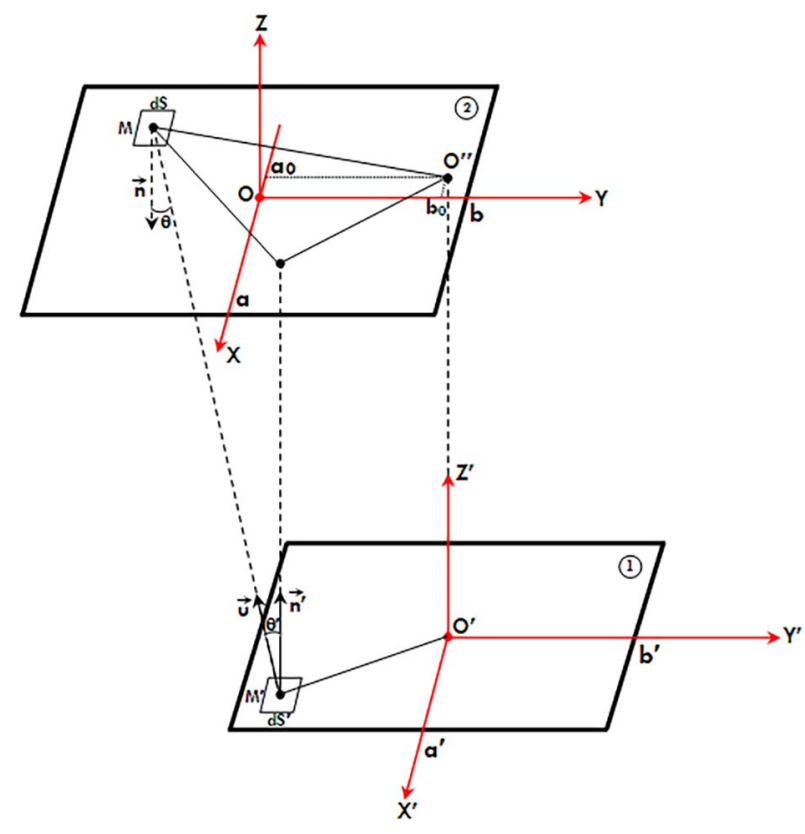

Fig. 2. descriptive diagram of the geometric problem: plane-parallel rectangular surfaces (Ritoux 2014)

Surfaces dimensions

$-a<X<+a,-b<Y<+b$,

$-a^{\prime}<X^{\prime}<+a^{\prime}, \quad-b^{\prime}<Y^{\prime}<+b^{\prime}$.

The form factor is calculated by solving the following integral (Ritoux 2014):

$F_{12}=\frac{1}{\pi S^{\prime}} \int_{S} \int_{S^{\prime}} \frac{\cos (\theta) \cos \left(\theta^{\prime}\right) d s d s^{\prime}}{r^{2}}=\frac{d^{2}}{\pi S^{\prime}} \iint_{S S^{\prime}} \frac{d s d s^{\prime}}{r^{4}}$.

In order to generalize the results, we introduce the reduced dimensions surfaces that are well noted.

$X=a / d, Y=b / d, X_{0}=a_{0} / d$,

$X^{\prime}=a^{\prime} / d, \quad Y^{\prime}=b^{\prime} / d, Y_{0}=b_{0} / d$.

Equation 25 becomes (Ritoux 2014):
With

$$
\begin{aligned}
& F(u, v)=u \sqrt{v^{2}+1} \operatorname{Arctg} \frac{u}{\sqrt{v^{2}+1}}+ \\
& v \sqrt{u^{2}+1} \operatorname{Arctg} \frac{v}{\sqrt{u^{2}+1}}-\frac{1}{2} \operatorname{Ln}\left(u^{2}+v^{2}+1\right) .
\end{aligned}
$$

This complex formula, but easy to program, is of the great importance. It contains all possible cases to calculate form factors of any flats, parallel surfaces, rectangular or square, centered or not.

The second case corresponds to rectangular surfaces forming a dihedral; an implicit scheme is illustrated in Figure 3. Assuming that:

$M M^{\prime}=r, O M^{\prime}=\rho^{\prime}\left(X^{\prime}, Y^{\prime}, 0\right), O M=\rho(0, Y, Z)$,

$\cos \theta^{\prime}=(Z / r), \cos \theta=X^{\prime} / r, r^{2}=X^{\prime 2}+\left(Y-Y^{\prime}\right)^{2}+Z^{2}$.

The form factor is calculated by solving the following integral (Ritoux 2014):

$$
F_{12}=\frac{1}{\pi S^{\prime}} \iint_{S^{\prime} S} \frac{X^{\prime} Z d s^{\prime} d s}{r^{4}} .
$$

Similarly, we introduce the following reduced coordinates.

$$
\mathrm{X}=a / b, \quad \mathrm{Z}=c / b .
$$

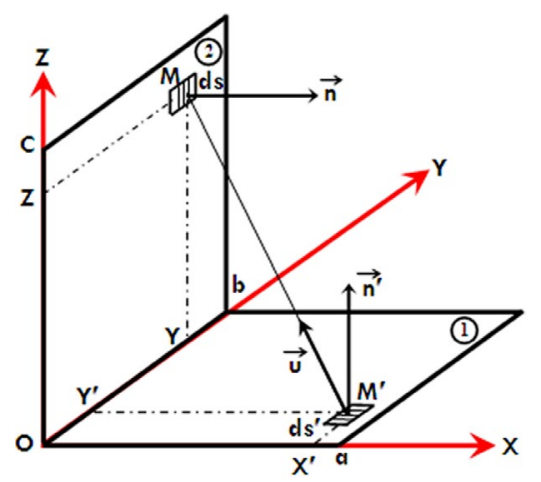

Fig. 3. descriptive diagram of the geometric problem: plane-parallel rectangular surfaces (Ritoux 2014)

$$
F_{12}=\frac{1}{8 \pi X^{\prime} Y^{\prime}}\left(\begin{array}{c}
F\left(X-X_{0}+X^{\prime}, Y-Y_{0}+Y^{\prime}\right)-F\left(X-X_{0}+X^{\prime}, Y-Y_{0}-Y^{\prime}\right)+F\left(X-X_{0}+X^{\prime}, Y+Y_{0}-Y^{\prime}\right)- \\
F\left(X-X_{0}+X^{\prime}, Y+Y_{0}-Y^{\prime}\right)-F\left(X-X_{0}-X^{\prime}, Y-Y_{0}+Y^{\prime}\right)+F\left(X-X_{0}-X^{\prime}, Y-Y_{0}-Y^{\prime}\right)- \\
F\left(X-X_{0}-X^{\prime}, Y+Y_{0}-Y^{\prime}\right)+F\left(X-X_{0}-X^{\prime}, Y+Y_{0}-Y^{\prime}\right)+F\left(X+X_{0}+X^{\prime}, Y-Y_{0}+Y^{\prime}\right)- \\
F\left(X+X_{0}+X^{\prime}, Y-Y_{0}-Y^{\prime}\right)+F\left(X+X_{0}+X^{\prime}, Y+Y_{0}-Y^{\prime}\right)-F\left(X+X_{0}+X^{\prime}, Y+Y_{0}-Y^{\prime}\right)- \\
F\left(X+X_{0}-X^{\prime}, Y-Y_{0}+Y^{\prime}\right)+F\left(X+X_{0}-X^{\prime}, Y-Y_{0}-Y^{\prime}\right)-F\left(X+X_{0}-X^{\prime}, Y+Y_{0}-Y^{\prime}\right)+ \\
F\left(X+X_{0}-X^{\prime}, Y+Y_{0}-Y^{\prime}\right) .
\end{array}\right) ;
$$


This leads to the following equation (Ritoux 2014):

$$
F_{12}=\frac{1}{4 \pi X}(F(X, Z)-F(X, 0)-F(0, Z)) .
$$

With

$$
\begin{aligned}
& F(u, v)=-4 \sqrt{u^{2}+v^{2}} \operatorname{Arctg} \frac{1}{\sqrt{u^{2}+v^{2}}}+ \\
& \left(u^{2}+v^{2}-1\right) \ln \left(u^{2}+v^{2}+1\right)-\left(u^{2}+v^{2}\right) \ln \left(u^{2}+v^{2}\right) .
\end{aligned}
$$

\section{Confrontation with experimental results}

The validation of this theoretical proposal will be a major contribution to provide a new simulation tool. Test procedure was carried out at Ghardaïa site. Ghardaïa Province (capital of the M'zab valley) is located in the center of the northern part of the Algerian Sahara desert at $32^{\circ} 30$ North altitude and longitude $3^{\circ} 45$. The fundamental nature of the Saharan climate is dry air, but microclimates play a considerable role in the desert with cold winter and hot summer. The annual average temperature is $22,46{ }^{\circ} \mathrm{C}$, with $34.85^{\circ} \mathrm{C}$ in July, the hottest month and $11.57^{\circ} \mathrm{C}$ in January for the coldest month. Winter temperatures vary between a maximum of $24^{\circ} \mathrm{C}$ and a minimum of $0{ }^{\circ} \mathrm{C}$. Its normal temperature in January is $10.4{ }^{\circ} \mathrm{C}$; it is $36.3^{\circ} \mathrm{C}$ in July. The average annual range is about $12.2^{\circ}$ amplitudes of monthly average temperatures. They are more moderate in winter than in summer (average $11^{\circ} \mathrm{C}$ in winter and $13.5^{\circ} \mathrm{C}$ in summer). This characterization is made from a synthesis climate of 10 years between 2002 and 2011. The average sunshine duration was 282.60 hours/month, with a maximum of 337.30 hours in July and a minimum of 234.50 hours in December. The average sunshine duration between 2000 and 2009 was 3391.20 hours/year i.e. approximately 9 hours/day. The relative humidity is very low; it is of the order of $21.60 \%$ in July, reaching a maximum of $55.80 \%$ in January and an annual average of $38.33 \%$. Solar radiation is intense throughout the year with a maximum of $700 \mathrm{Wm}^{2}$ in winter and $1000 \mathrm{Wm}^{2}$ in summer, measured on the horizontal surface (Yaiche et al. 2014).

The proposed study is focused on an unoccupied office working during the measurement phase at the Applied Research Unit in Renewable Energy. This single-area has a living space of $15.98 \mathrm{~m}^{2}(4.7 \times 3.4)$, the height of the walls is $3.5 \mathrm{~m}$. For this study, the south wall is exposed to the outside environment, consists of a heavy stone of $40 \mathrm{~cm}$ thick surrounded by two lay- ers having a thickness of $1.5 \mathrm{~cm}$ of plaster and $1 \mathrm{~cm}$ of cement mortar covered by an interior finish coating. The inner walls separating the office working from the hall are considered as cinderblock structures surrounded by two thick layers of cement mortar $(1.5 \mathrm{~cm})$ and two other finishing coat layers (coated gypsum). Dimensions of the door are $2.2 \times 0.94 \mathrm{~m}$, the window surface is approximated to a rectangular shape with a surface area of $1 \mathrm{~m}^{2}$. Door and window are made of wood with a thickness of $2 \mathrm{~cm}: \lambda=0.14 \mathrm{~W} \mathrm{~m}^{-1} \mathrm{~K}^{-1}$, $\rho=500 \mathrm{~kg} \mathrm{~m}^{-3}$ and $\mathrm{Cp}=2500 \mathrm{~J} \mathrm{~kg}^{-1} \mathrm{~K}^{-1}, \lambda, \rho$ and $\mathrm{Cp}$ are respectively thermal conductivity, density and specific heat, each wall type is described in Table 1. Some thermal properties of the materials are the usual values found in reference (Bekkouche et al. 2014, 2013a, 2013b, 2011, 2009; Bekkouche 2009; Hamdani et al. 2014; Haddam et al. 2015).

In this part, obtaining data was provided using four calibrated weather stations with high precision. The temperature sensors were placed taking into account the air stratification phenomenon. The collection of the external environment data will be by transmission.

To perform this study, we chose the days from December 27, 2014 to January 2, 2015. The incident solar radiation on a horizontal surface and for a vertical plane facing South, North, East, and West was determined using numerical models (Yaiche et al. 2014). The curve of the incident solar irradiation in Figure 5 a proves that these days correspond to a clear sky. The ambient temperature is between 04 and $17^{\circ} \mathrm{C}$ (Fig. 5b), the relative humidity ranges from $30 \%$ to $65 \%$ (Fig. 5c). Figure $5 \mathrm{~d}$ shows that the wind velocity undergoes a random behavior; peaks can exceed the value of $39 \mathrm{~m} \mathrm{~s}^{-1}$.

The solar radiation received on a surface depends on the orientation of the surface. A normal surface facing east will receive direct solar radiation at sunrise, while a vertical surface facing west only receives direct

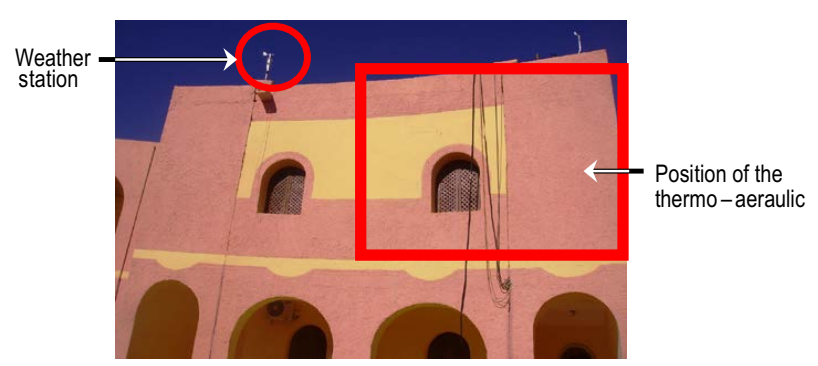

Fig. 4. General photo describing the office working position 
a)

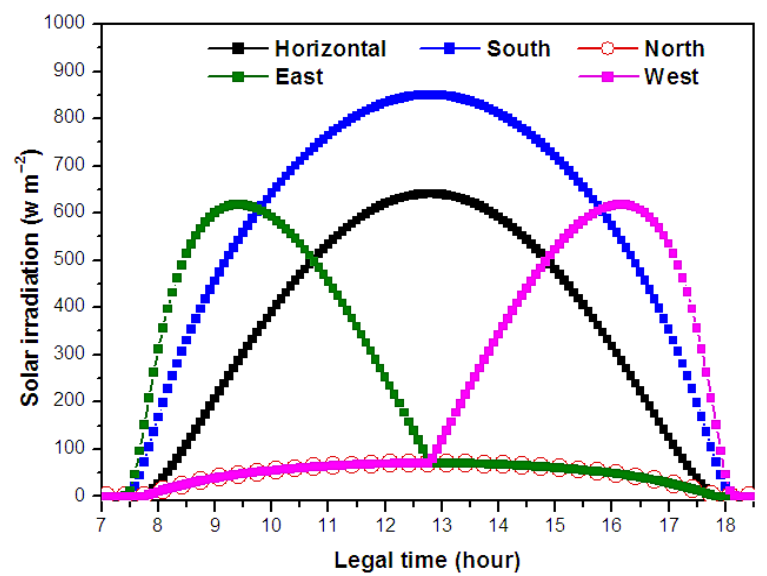

c)

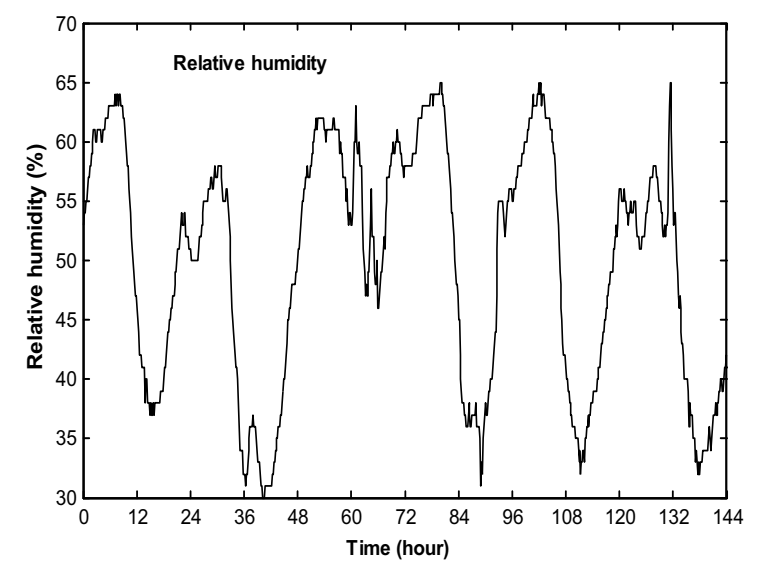

b)

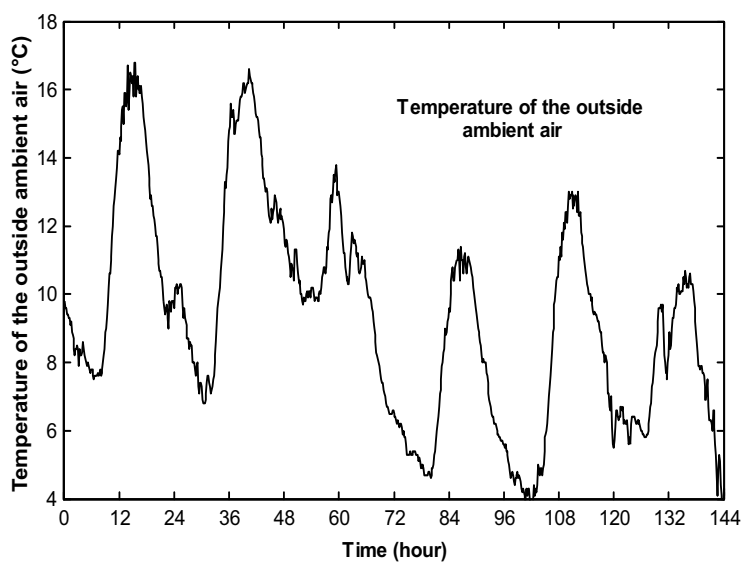

d)

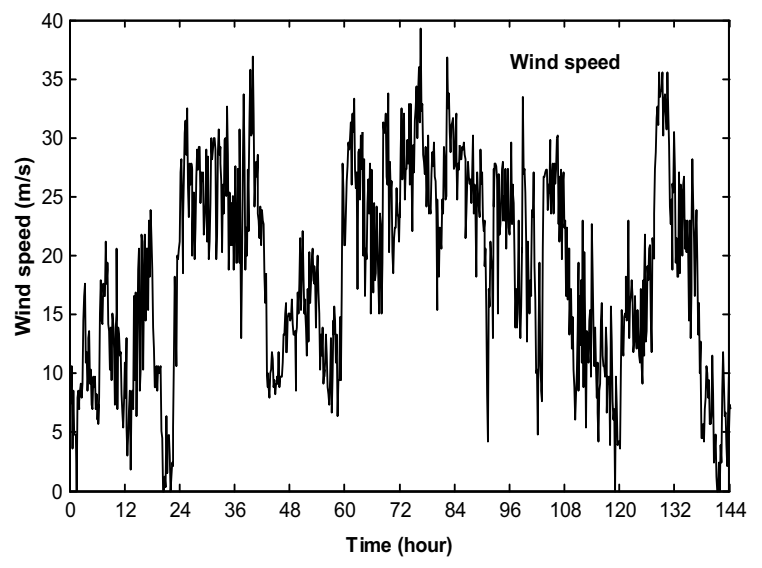

Fig. 5. Radiometric and weather data from December 27, 2014 to January 2, 2015: (a) Incident solar irradiation, 30 December; (b) Ambient temperature, (c) relative humidity, (d) wind speed

radiation after noon (when the sun passes its zenith). A horizontal surface can receive solar radiation during the whole day when no shadowing from the surrounding area appears. As can be seen in Figure 5a, a south facing will receive the most radiation.

The application below is an example which illustrates the reach level of the thermo-aeraulic comfort in Ghardaïa site. We derive our predictions by displaying the results of numerical simulations. Also, the proposed model is based on the thermal nodal method (Bekkouche et al. 2013a) which is very widespread because it requires a reduced memory capacity; allows to have results in a relatively short time. The resolution of the nonlinear differential Equations (11), (15), (22), (23), and (24) system is performed by the Runge-Kutta method. Solutions of the equations system will allow us to determine the temperature and relative humidity of the air. The comparison of the measured and predicted temperatures using the meteorological data is shown in Figures 6 and 7.

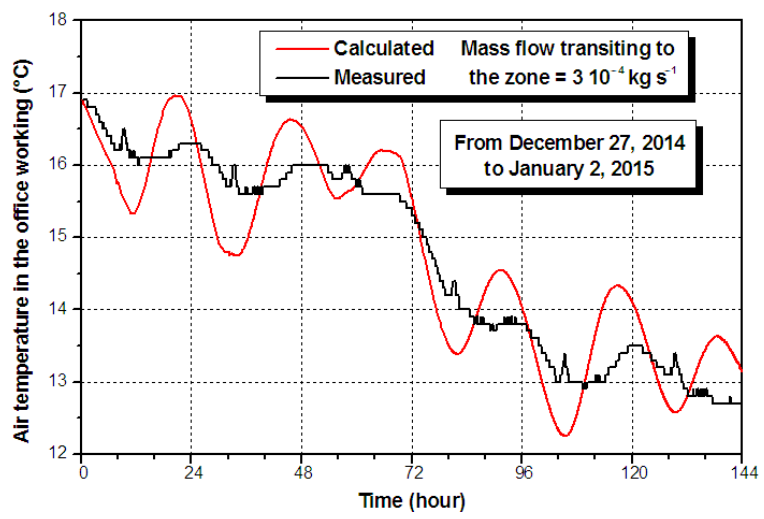

Fig. 6. Simulated and measured temperature of air in the office working

According to these results, the relative algebraic error is less than $8.7787 \%$ for the air temperature; the minimum relative error is $0.0050 \%$ and its average value equal to $3.5752 \%$. The average difference in temperature equal to $0.5102{ }^{\circ} \mathrm{C}$, the absolute error varies between $7.996110^{-4}{ }^{\circ} \mathrm{C}$ and $1.3652^{\circ} \mathrm{C}$. However, indicative curves representing the relative humidity pro- 
files designate that the mean relative algebraic error, minimum and maximum relative error committed are respectively $2.4661 \%, 0.0023 \%$ and $6.8791 \%$. The average difference in relative humidity equals $0.8950 \%$, the absolute error ranges from $7.930710^{-4} \%$ to $2.4076 \%$. Following this study, the comparison between the measured and the computed values is acceptable.

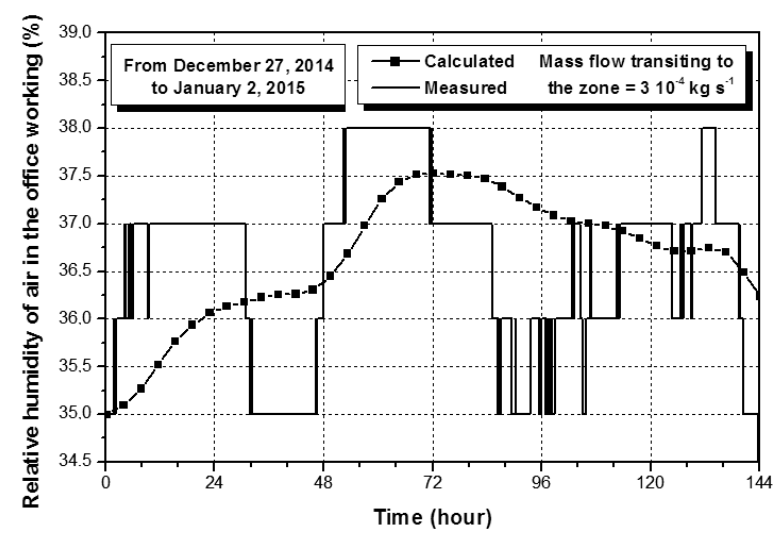

Fig. 7. Simulated and measured relative humidity of air in the office working

Previous works (Hamdani et al. 2014; Bekkouche et al. 2013b; Haddam et al. 2015), we have previously reported that a high thermal inertia of a heavy stone construction characterized by poor compactness in Saharan climate can play a negative role in term of thermo-aeraulic comfort for extreme weather conditions. However, in addition to the known formulas that characterize the thermal inertia, we also find precious indices that are the inner surface temperatures of walls, which allow to concretely assess the thermal inertia level of such construction. Thereafter we can explain this phenomenon by taking into account this aspect; these deduced results describe the thermal state of the exterior envelope. In these situations, such as result will be classified the different cases according to the energy storage capacity of the opaque walls in contact with the outside. Consequently, we will be sure to decide that if the initial temperatures are sufficiently low, we can consider that we are in the vicinity of the thermal storage threshold. During this week, even if the sky is totally clear, night time is always long compared to the diurnal period because the sunshine duration is about $10 \mathrm{~h} 06 \mathrm{~min}$. These data lead to a permanent and an intense absorption of the cold compared to the solar radiation. In this case, the observed initial temperatures decrease continuously, this is explained by the first unfavorable external climatic conditions that influenced interior temperatures through infiltration. The inside flow of cold air is caused by the high speed of the wind. Secondly this situation is explained also by the threshold of the thermal inertia level which is not yet reached, and thirdly by poor compactness of this office (index compactness $=1.2995$ ) promoting easily heat loss. All these unfavorable conditions certainly excite indoor temperature fluctuations to decrease rapidly.

\section{Comparative study of temperature using TRNSYS software}

The study was carried out on a building in URAER Ghardaïa. Figure 8 is a schematic outline of apartment building, it has a surface of $95.74 \mathrm{~m}^{2}$ with a living space of $71.3 \mathrm{~m}^{2}$, and wall heights are equal to $2.8 \mathrm{~m}$. A given building is composed of a certain number of

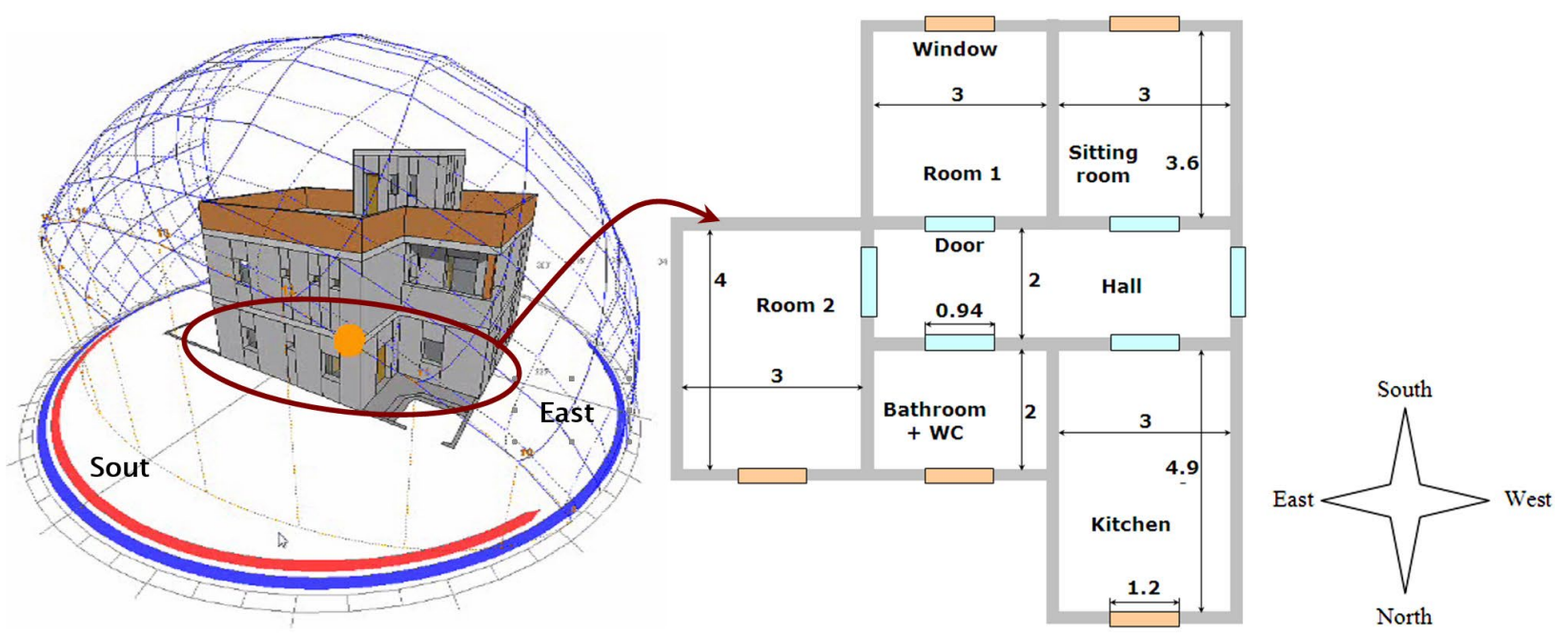

Fig. 8. Diagram, solar path and descriptive plane 
rooms, walls, doors and also glass-windows. Layer thickness, composition and thermal transmittance values $U$ for walls, ground and roof and glass thermal transmittance values are given in references (Yaiche et al. 2014; Bekkouche et al. 2014, 2013a, 2013b, 2011, 2009; Hamdani et al. 2014; Bekkouche 2009). In these works, the diagram and the solar path serve to identify the shade and particularly the influence of the shade of walls on the other opaque walls.

Therefore, the splitting up of the building into thermal zones induces the setting of nodes of temperature by zone. We have been induced to assign a type to each node. The nodes are concerned with different phenomena. Bekkouche et al. (2013a), give the types of nodes encountered. For a given building, when the node structure is established, it is easy to fill up each element of the mathematical model. The structure will include six zones' numbers.

The most commonly used indicator of thermal comfort is air temperature, it is easy to use and most people can relate to it. Air temperature should always be considered in relation to other environmental factors: radiant temperature, air velocity and humidity. The advantage of our proposed model is that these four factors were taken into consideration. In this section, we will focus only on the validation of the internal temperature of a building area using the TRNSYS software. The developed mathematical model is formulated by Equations (16), (20), (28), (29), and (30). We are getting a non stand alone system governed by one hundred and forty one non linear ordinary differential equations. Runge Kutta fourth order numerical method was used to apprehend thermal behavior of walls and air subjected to varied solicitations.
TRNSYS is a software designed to the dynamic simulation of solar systems. All simulated system is shown in Figure 9. Modules appearing in the figure are used to draw solicitations from Ghardaïa meteorological data for 2013.

To make this comparison, we chose the days of 20-25 July 2013; these days correspond generally to a clear sky, an ambient temperature between 29 and $45{ }^{\circ} \mathrm{C}$ (Fig. 10a) and relative humidity between 7 and $45 \%$ (Fig. 10b). Figure 10c presents the wind velocity profile. The incident solar radiation on a horizontal surface and for a vertical plane facing South, North, East, and West was determined using numerical models (Yaiche et al. 2014) and given in Figure 10d.

To assess the proposed approach, it is judicious to estimate the absolute error, the relative algebraic error and the root mean square error. RMSE is a used measure of the differences between values predicted by a model and the measured values, is defined as the square root of the mean square error:

$$
\text { RMSE }=\sqrt{\frac{1}{N} \sum_{L=1}^{L=N}\left(T_{\text {measured }}-T_{\text {calculated }}\right)^{2}} .
$$

where $N$ - number of measurements

Figure 11 gives an overview of the air temperature in the sitting room for a mass flow equal to $10^{-3} \mathrm{~kg} / \mathrm{s}$.

Assuming that the values calculated by TRNSYS are the reference temperatures, we can do error calculations that are actually meaningful to our comparison. The root mean square error equals $0.6252^{\circ} \mathrm{C}$, and we also find that the mean absolute and relative errors are respectively equivalent to $0.2592{ }^{\circ} \mathrm{C}$ and $0.77 \%$. These small perturbations are usually due to the state of the sky and outdoor ambient. To calculate the solar

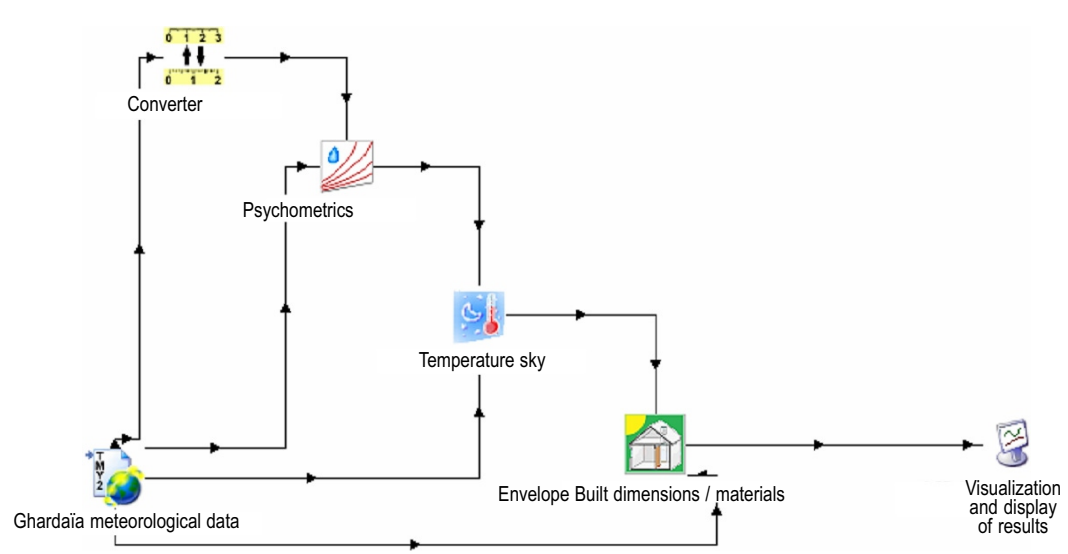

\begin{tabular}{|c|c|c|}
\hline $\begin{array}{c}\text { Symbol } \\
\text { module }\end{array}$ & Type & Real mode \\
\hline & Type 109-TMY2 & $\begin{array}{c}\text { Ghardaïa } \\
\text { meteorological } \\
\text { data }\end{array}$ \\
\hline & Type 57 & Converter \\
\hline & Type 69b $33 \mathrm{~b}$ & Psychometrics \\
\hline & $\begin{array}{c}\text { Type 56d } \\
\text { Temperature sky }\end{array}$ & $\begin{array}{c}\text { Envelope Built } \\
\text { dimensions / materials }\end{array}$ \\
\hline
\end{tabular}

Fig. 9. Implementation of the model in TRNSYS \& relationship between TRNSYS and real mode 
irradiance, we considered that the sky is completely clear. Also, the followed methods may be the source of these disturbances. The Interpolation method can significantly reduce program execution time, but it can sometimes influence the accuracy of calculations, especially in the presence of complex random behavior. This is exactly the case of the instantaneous variation of the wind speed; we can see this aspect specifically around the time interval between 68 and 73 hours where the absolute error can reach the value of $2.01^{\circ} \mathrm{C}$.

This error margin is certainly caused by the peak wind speed occurred and observed before this interval (68 hours before). This aspect refers to the concept and the high thermal inertia of the building, which is characterized by a strong phase of internal temperatures. The envelope is composed of heavy opaque walls with a thickness of more than $40 \mathrm{~cm}$ (see Bekkouche et al. 2014, 2013a, 2013b, 2011, 2009; Hamdani et al. 2014; Bekkouche 2009).

a)

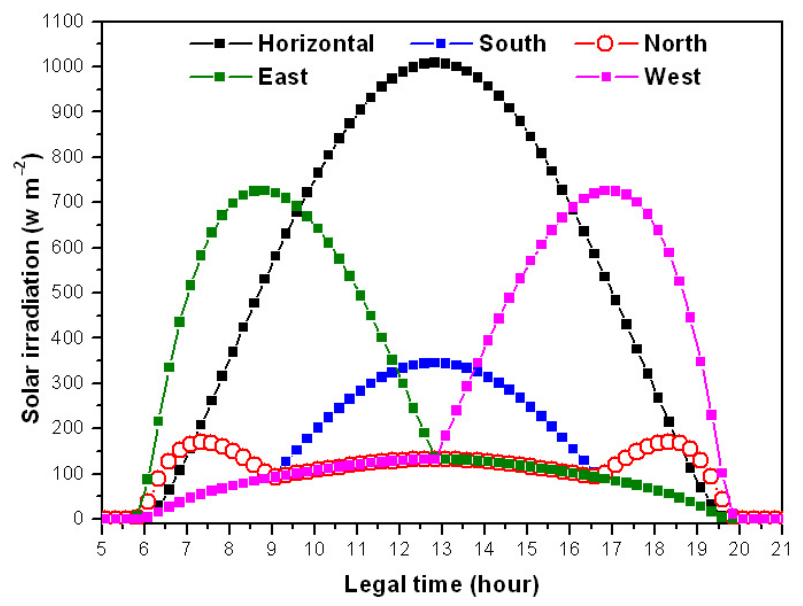

c)

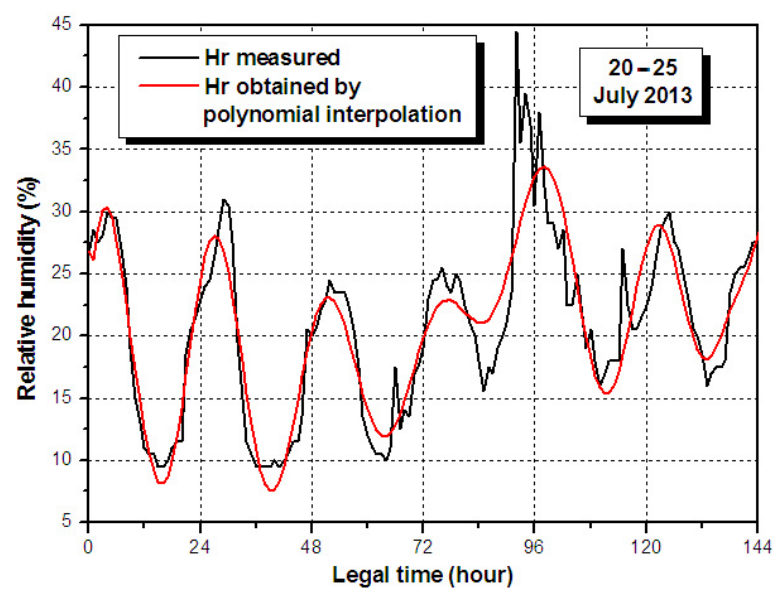

It should be noted that the difference between the measured value and obtained by interpolation (nonlinear regression) of the wind speed can reach the order of $5.5 \mathrm{~m} / \mathrm{s}$, which is really meaning. To solve and avoid the problem posed by these considerations, we require in future research, rigorous discretization of time interval, depending on the complexity of the climate variable in terms of polynomial interpolation. This method will increase the execution time of the program but it allows for more precision in calculations.

For the winter period, we chose the days of 21-26 December 2013. The ambient temperature plotted in Figure $12 \mathrm{a}$ achieves low values (up to $3{ }^{\circ} \mathrm{C}$ ). The relative humidity is between 17 and $65 \%$ (Fig. 12b). The wind speed is generally less than $6 \mathrm{~m} \mathrm{~s}^{-1}$ (Fig. 12c). Figure 13 shows predicted temperatures by the two identified model; represents temperatures curves of the internal air.

b)

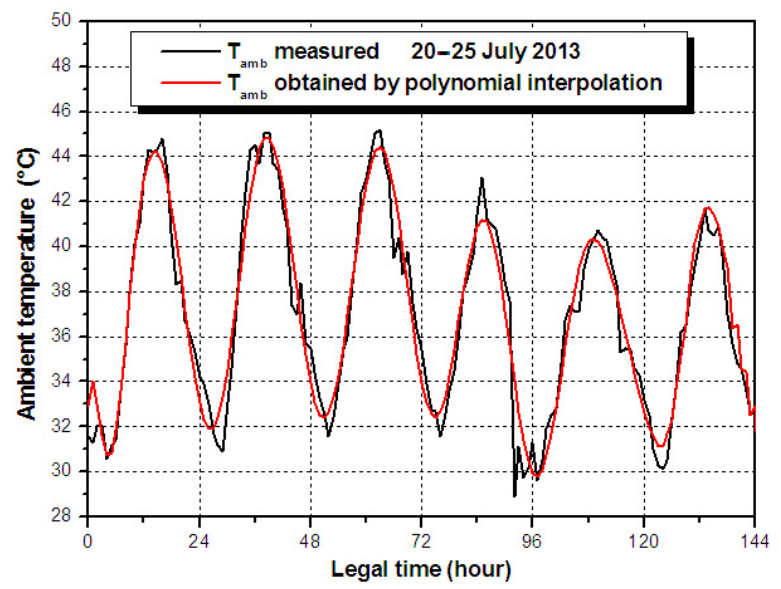

d)

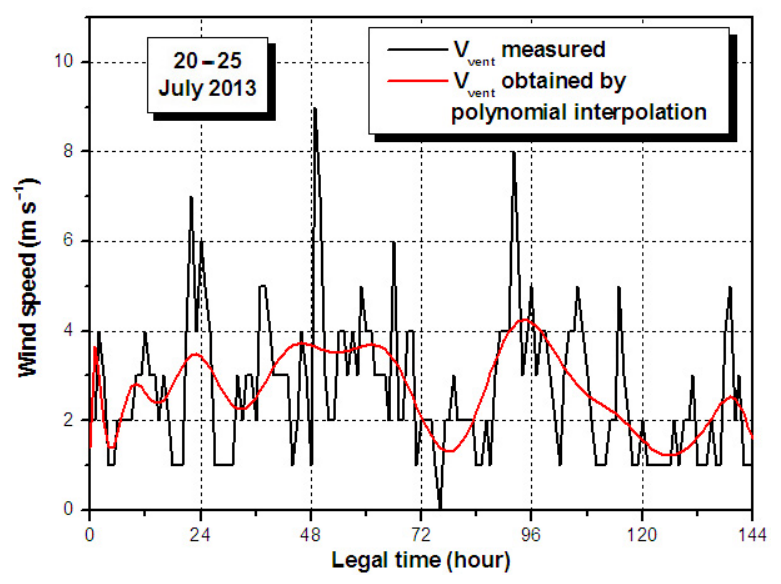

Fig. 10. Radiometric and weather data 20-25 July 2013: (a) Incident solar irradiation, 23 July; (b) Ambient temperature, (c) relative humidity, $(\mathrm{d})$ wind speed 


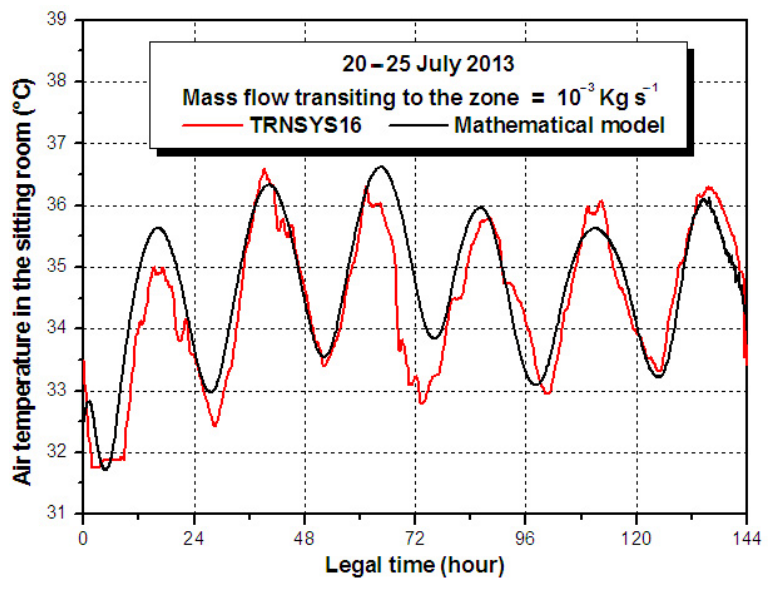

Fig. 11. Air temperature in the sitting room

The agreement for this example seems better than the previous example. The root mean square error equals to $0.2908^{\circ} \mathrm{C}$, the mean absolute and relative errors are respectively equivalent to $0.0728{ }^{\circ} \mathrm{C}$ and $0.52 \%$. These findings are undoubtedly due to the behavior of the wind speed that is not identical to the first case. The intensity of the random behavior is not important when compared to the observed complexity level in the first example.

\section{Comparative study according to the level-compactness}

The main impact of building compactness is its effect on the envelope's surface area, relative to the floor's area, or the space volume, and hence, the rate of heat exchange of the building with the outdoors. Compactness measures can be defined typically as functions of volume and surface area. The most common compactness measures are a function of the compactness quotient, indicated by the $\mathrm{S} / \mathrm{V}$ ratio, $\mathrm{S}$ : area of building envelope surface, V: volume of the building (Suárez et al. 2008).

Several studies (Bekkouche et al. 2013a; Haddam et al. 2015) have proved that this factor is a very determinant index for thermal comfort. In this context we want to see how the wall height may affect the indoor thermo-aeraulic comfort of the building. We are interested primarily in the identification of two essential parameters of the comfort (temperature and specific humidity) by varying the size of opaque walls. We consider in this case that this habitat is a house with two facades so automatically each room has one exposed wall. By using using Equations (26) and (29), we can a)

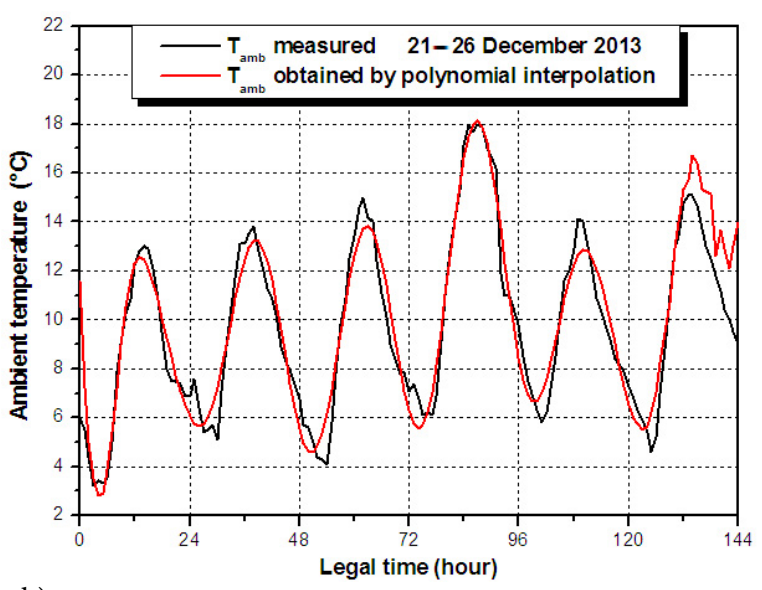

b)

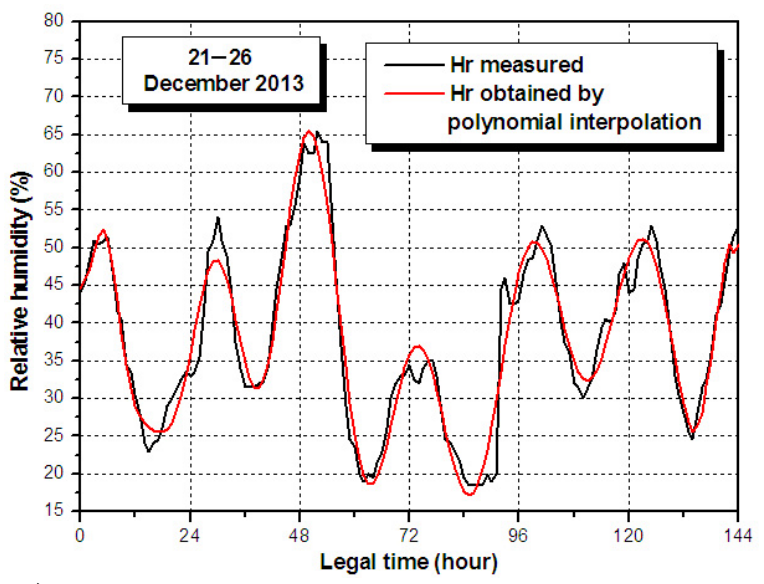

c)

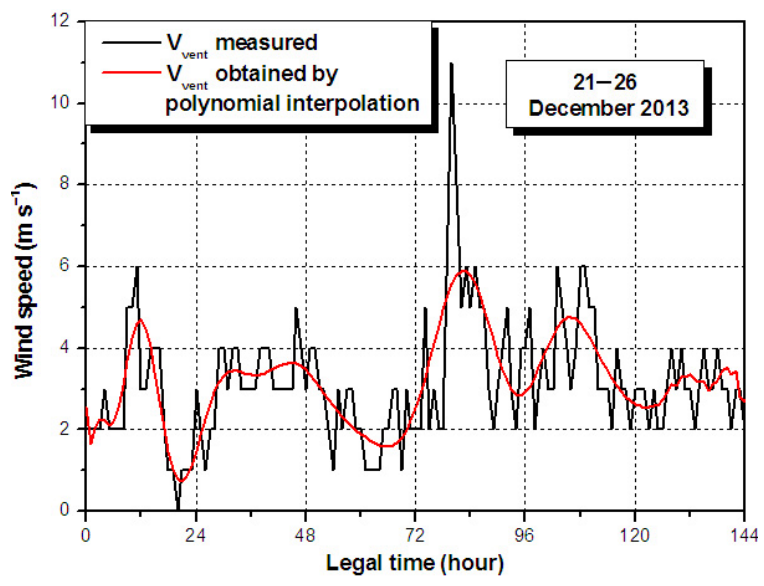

Fig. 12. Weather data 21-26 December 2013: (a) Ambient temperature, (b) relative humidity, (c) wind speed

achieve the exact values of the form factor. Figures 14 and 15 give an idea of the temperature and specific humidity profiles obtained by numerical simulation by keeping the same descriptive plane but by varying the height of the walls. The days of 20-25 July 2013 were selected to perform this study. 


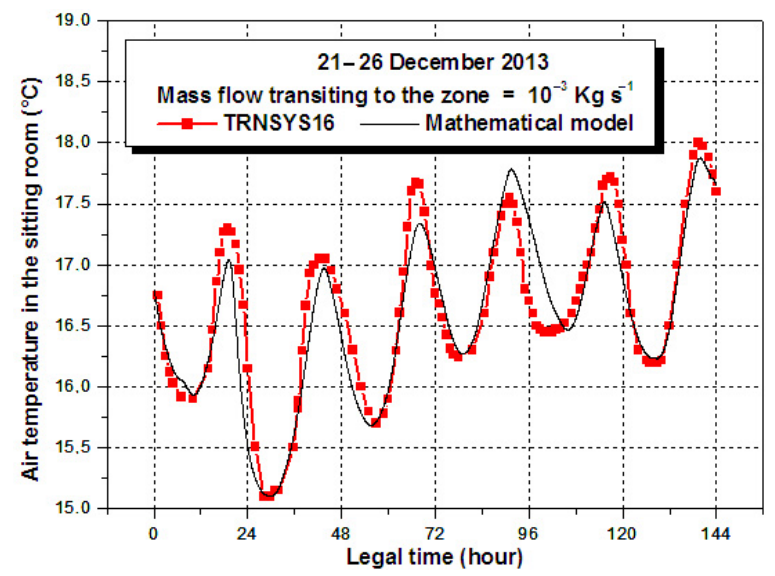

Fig. 13. Air temperature in the sitting room

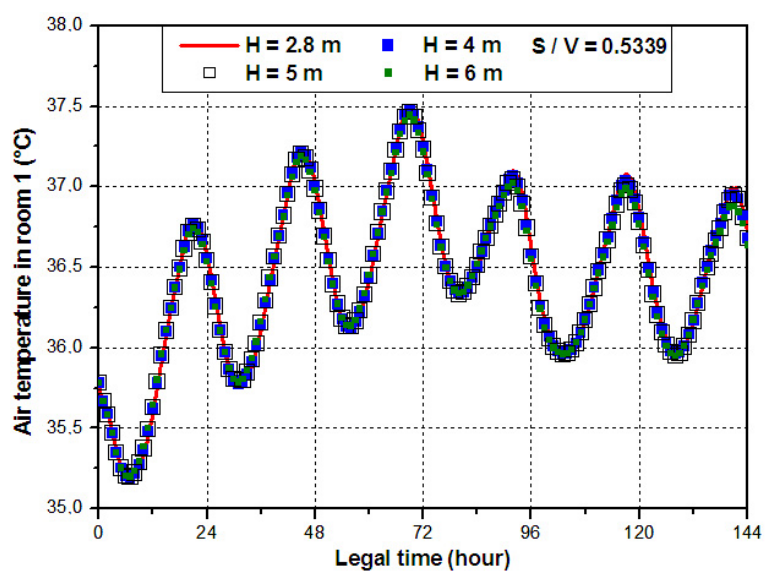

Fig. 14. Air temperature in room 1

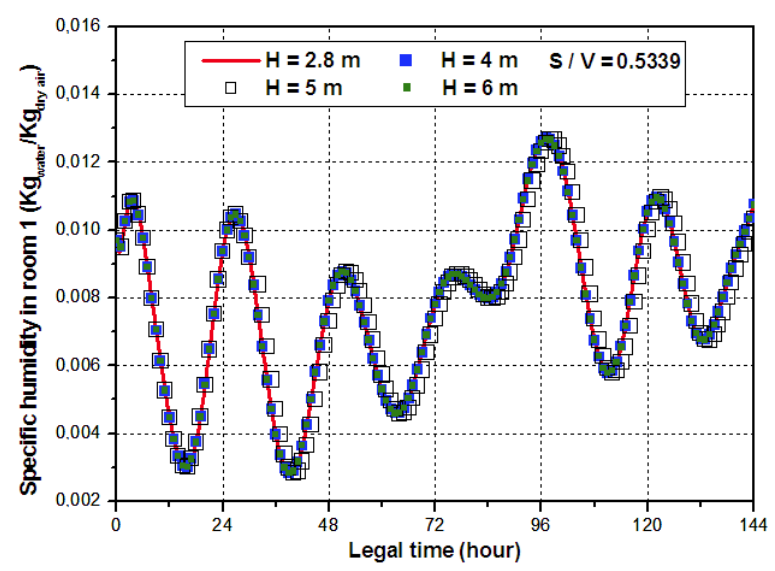

Fig. 15. Specific humidity in room 1

Only the facades were considered exposed to different climatic conditions. By varying the height of the walls, the compactness index of each room does not change and remains constant. The calculation of the compactness index for the four cases is given in previous figures that predict the calculated temperatures and specific humidity using the same previous conditions. Knowing the importance of this index, the numerical performance of this new approach is tested. The curves are very similar and almost confused. These results were expected because numerical simulations were conducted in the same initial and climatic conditions and thermophysical properties of the envelope. Hence, the changes were made only at the geometry level ensuring a constant compactness index for each room alone.

\section{Conclusions}

Thermo-aeraulic modelling is essential for establishing overall thermal performance values and understand how different assembly designs perform under different interior and exterior climate conditions. It is concluded that models offer a valuable decision support system for designers at an early design state for the optimization of the passive thermal performance achieving optimum thermal comfort and savings in heating and cooling energy in Saharan region. We confirm with using confrontational methods included in section 5 and 6 that this new approach will be used to evaluate the thermal performance of a proposed architecture for a real building located in a very hot climate. The comparison proves as a whole acceptable. This margin is justified by the weather which is not stable: wind speed varies greatly in very complex ways. The input data, i.e., ambient temperature and wind speed were included in the program by determining an interpolation function (polishing polynomial) that identifies each parameter to ensure the execution speed of the program designed. The prediction of air temperatures from this model of a whole building is a step forward in the simulation process that helps the comprehension of the building behavior, the improvement of the building envelope, and the estimation of the comfort levels in side it. This simplified method is a good approach to the understanding of the thermal behavior of air in a real building. But sometimes (in the presence of climatic disturbances), it should be noted that it is essential to integrate temporal discretizations to achieve high accuracy.

Some variables that are related to building shape and which influence heating and cooling requirements are the following: compact ness index, the height of walls, climate, and the characteristics of the building envelope. These characteristics are crucial variables that should be taken into account because they are relevant to the energy requirements for maintaining the 
building at a comfortable temperature. In section 7, it is proved once again that the main impact of building compactness from the indoor climate point of view is its effect on the envelope's surface area, relative to the floor's area, or the space volume, and hence, the rate of heat exchange of the building with the outdoors. For the same conditions, when the compactness index of both a multizone building and each zone of this building is kept constant, this situation not causes a change in the interior thermo-aer aulic comfort. According to the results found in this section, we can test one reliability index of any model of comfort by comparing it for other buildings characterized by the same compactness indices and under the same climatic and initial conditions.

Finally, to give more importance to this digital tool, we think that the test of this model for other sites with different climatic regimes seems very essential; the generalisation of its use can open multiple perspectives.

\section{References}

AlAnzi, A.; Seo, D.; Krarti, M. 2009. Impact of building shape on thermal performance of office buildings in Kuwait, Energy Conversion and Management 50: 822-828.

http://dx.doi.org/10.1016/j.enconman.2008.09.033

Bekkouche, S. M. A.; Benouaz, T.; Cheknane, A. 2009. A modelling approach of thermal insulation applied to a Saharan building, Thermal Science 13(4): 233-244.

http://dx.doi.org/10.2298/TSCI0904233B

Bekkouche, S. M. A.; Benouaz, T.; Cherier, M. K.; Hamdani, M.; Benamrane, N.; Yaiche, M. R. 2014. Thermal resistances of local building materials and their effect upon the interior temperatures case of a building located in Ghardaïa region, Construction and Building Materials 52: 59-70. http://dx.doi.org/10.1016/j.conbuildmat.2013.10.052

Bekkouche, S. M. A.; Benouaz, T.; Cherier, M. K.; Hamdani, M.; Yaiche, M. R.; Benamrane, N. 2013a. Influence of the compactness index to increase the internal temperature of a building in Saharan climate, Energy and Buildings 66: 678-687. http://dx.doi.org/10.1016/j.enbuild.2013.07.077

Bekkouche, S. M. A.; Benouaz, T.; Cherier, M. K.; Hamdani, M.; Yaiche, M. R.; Khanniche R. 2013b. Influence of building orientation on internal temperature in Saharan climates, building located in Ghardaïa region (Algeria), International Scientific Journal, Thermal Science 17(2): 349-364. http://dx.doi.org/10.2298/TSCI110121112B

Bekkouche, S. M. A.; Benouaz, T.; Yaiche, M. R.; Cherier, M. K.; Hamdani, M.; Chellali, F. 2011. Introduction to control of solar gain and internal temperatures by thermal insulation, proper orientation and eaves, Energy and Buildings 43: 2414-2421. http://dx.doi.org/10.1016/j.enbuild.2011.05.018

Bekkouche, S. M. A. 2009. Modélisation du comportement thermique de quelques dispositifs solaires: Thèse de Doctorat en Physique Electronique et Modélisation. Université Abou Bekr Belkaïd, Tlemcen, Algeria.
Depecker, P.; Menezo, C.; Virgone, J.; Lepers, S. 2001. Design of buildings shape and energetic consumption, Building and Environment 36:627-635. http://dx.doi.org/10.1016/S0360-1323(00)00044-5

Goyal, S.; Barooah, P. 2012. A method for model-reduction of non-linear thermal dynamics of multi-zone buildings, Energy and Buildings 47: 332-340. http://dx.doi.org/10.1016/j.enbuild.2011.12.005

Granadeiro, V.; Duarte, J. P.; Correia, J. R.; Vítor M. S. L. 2013. Building envelope shape design in early stages of the design process: Integrating architectural design systems and energy simulation, Automation in Construction 32: 196-209. http://dx.doi.org/10.1016/j.autcon.2012.12.003

Haddam, M. A. C.; Bekkouche, S. M. A.; Benouaz, T.; Hamdani, M.; Cherier, M. K.; Benamran N. 2015. Integration of eaves and shading devices for improving the thermal comfort in a multi-zone building, Thermal Science 19(Suppl 2): S615-S624. http://dx.doi.org/10.2298/TSCI140422117H

Hamdani, M.; Bekkouche, S. M. A.; Benouaz, T.; Belarbi, R.; Cherier, M. K. 2014. Minimization of indoor temperatures and total solar insolation by optimizing the building orientation in hot climate, Engineering Structures and Technologies 6(3): 131-149. http://dx.doi.org/10.3846/2029882X.2014.988756

Jannot, Y. 2012. Cours Transferts thermiques, $2^{\mathrm{ème}}$ année Ecole 2 des Mines Nancy, France, Edilivre ISBN 978-2-332-83699-1

Lauret, P.; Boyer, H.; Riviere, C.; Bastide, A. 2005. A genetic algorithm applied to the validation of building thermal models, Energy and Buildings 37: 858-866. http://dx.doi.org/10.1016/j.enbuild.2004.11.006

Mathews, E. H.; Richards, P. G.; Lombard, C. 1994. A first-order thermal model for building design, Energy and Buildings 21: 133-145. http://dx.doi.org/10.1016/0378-7788(94)90006-X

Mora, L. 2003. Prédiction des performances thermo-aérauliques des bâtiments par association de modèles de différents nivea$u x$ de Finesse au sein d'un environnement orienté: Thèse de Doctorat. Laboratoire d'Etude des Phénomènes de Transfert Appliqués au Bâtiment, UFR Sciences Fondamentales et Sciences pour l'Ingénieur, Université de la Rochelle, France.

Ritoux, G. 1982. Evaluation numérique des facteurs de forme, Revue de Physique Appliquée 17: 503-515. http://dx.doi.org/10.1051/rphysap:01982001708050300

Roux, J. J. 2000. Comportement thermique des bâtiments. Institut National des Sciences Appliquées, département de génie civil, INSA de Lyon.

Rumianowski, P.; Brau, J.; Roux, J. J. 1989. An adapted model for simulation of the interaction between a wall and the building heating system, in Proceedings of the Thermal Performance of the Exterior Envelopes of Buildings IV Conference, 4-7 December 1989, Orlando, Florida, USA, 224-233.

Sourbron, M.; Helsen, L. 2011. Evaluation of adaptive thermal comfort models in moderate climates and their impact on energy use in office buildings, Energy and Buildings 43: 423432. http://dx.doi.org/10.1016/j.enbuild.2010.10.005

Suárez, J.; Gancedoa, E.; Âlvarez, J. M.; Morán, A. 2008. Optimum compactness structures derived from the regular octahedron, Engineering Structures 30: 3396-3398. http://dx.doi.org/10.1016/j.engstruct.2008.04.030 
Wang, W.; Rivard, H.; Zmeureanu, R. 2006. Floor shape optimization for green building design, Advanced Engineering Informatics 20: 363-378. http://dx.doi.org/10.1016/j.aei.2006.07.001

Yaiche, M. R.; Bouhanika, A.; Bekkouche, S. M. A.; Malek, A.; T. Benouaz, 2014. Revised solar maps of Algeria based on sunshine duration, Energy Conversion and Management 82: 114-123. http://dx.doi.org/10.1016/j.enconman.2014.02.063

\section{Nomenclature}

$$
\begin{aligned}
S- & \text { surface }\left(\mathrm{m}^{2}\right) ; \\
j- & \text { number of the inner surface (wall, door } \\
& \text { and window ) in zone } i \text {; } \\
N W(i)- & \text { total number of the interior surfaces } \\
& \quad \text { (wall, door and window ) in zone } i ; \\
T_{a l}(n)- & \text { air temperature of the zone } n=\text { air tempé- } \\
& \text { rature entering the zone } i(\mathrm{~K}) ; \\
T_{s i j}, T_{A}- & \text { temperature of surface } j \text { in zone } i(\mathrm{~K}) ; \\
H_{s}, r_{s}(i)- & \text { specific humidity: mass of water vapor } \\
& \text { contained in the unit mass of dry air } \\
& \left(\operatorname{kg}_{v a p} / \mathrm{kg}_{a s}\right. \text { or \%); } \\
H_{r}- & \text { relative humidity (\%); } \\
P_{s a t}- & \text { pressure of saturation vapor }(\mathrm{Pa}) ; \\
L_{v}- & \text { latent heat of vaporization of water }(\mathrm{J} \\
& \left.\mathrm{Kg}^{-1}\right) ; \\
C_{v}- & \text { heat capacity at constant volume } \\
& \left(\mathrm{J} \mathrm{Kg}^{-1} \mathrm{~K}^{-1}\right) ; \\
C_{a s}- & \text { heat capacity of the air mass }\left(\mathrm{J} \mathrm{Kg}^{-1} \mathrm{~K}^{-1}\right) ; \\
r_{s}(i)- & \text { specific humidity: mass of water vapor } \\
& \text { contained in the unit mass of dry air } \\
& \left(\mathrm{kg}_{v a p} / \mathrm{kg}_{a s}\right. \text { or \%); }
\end{aligned}
$$

$H^{e}(i)$ - enthalpy of the humid air mass entering the zone $i(\mathrm{~J})$;

$H^{s}(i)$ - enthalpy of the humid air mass leaving the zone $i(\mathrm{~J})$;

$\mathrm{Q}_{\text {mas }}^{e}(n, i)-$ mass flow transiting from zone $n$ to zone $k(\mathrm{Kg} / \mathrm{s})$;

$\mathrm{Q}_{\text {mas }}^{s}(i, n)$ - mass flow of the dry air transiting from zone $i$ to zone $n(\mathrm{Kg} / \mathrm{s})$;

$C I_{s}, C I_{e}$ - internal sensitive and latent powers due to appliances, occupants, lighting...(W);

$P_{s}+P_{l}-$ sensitive and latent powers provided by the air-conditioning $(\mathrm{W})$;

$V(i)$ - volume of zone $i$;

$v_{s}(i)$ - specific volume of the humid air in the zone $i$;

$e$ - thickness (m);

$n$ - number of node;

$\alpha$ - absorption coefficient;

$\varepsilon$ - thermal emissivity;

$G$ - the incident global irradiation on the surfaces $\left(\mathrm{W} \mathrm{m}^{-2}\right)$;

$\lambda$ - thermal conductivity $\left(\mathrm{W} \mathrm{K}^{-1} \mathrm{~m}^{-1}\right)$;

$c_{p}$ - specific heat $\left(\mathrm{J} \mathrm{kg}^{-1} \mathrm{~K}^{-1}\right)$;

$\rho$ - density $\left(\mathrm{kg} \mathrm{m}^{-3}\right)$;

$F$ - form factor between the exchange surfaces;

$\sigma$ - Stephane-Boltzmann constant $\left(\mathrm{W} \mathrm{m}^{-2} \mathrm{~K}^{-4}\right)$;

$h_{\text {conv }}$ - convective transfer coefficients $\left(\mathrm{W} \mathrm{m}^{-2} \mathrm{~K}^{-1}\right)$.

Sidi Mohammed El Amine BEKKOUCHE. Born in Nedroma (Tlemcen, Algeria), MSc in Tlemcen University (2006), holds a PhD degree in Physics at Tlemcen University (2009). He was a student of Professor Tayeb BENOUAZ, he works as researcher in Applied Research Unit on Renewable Energies "URAER Ghardaia", research team: solar and bioclimatic architecture. His research field is computational physics, modeling in physics and simulation of the nonlinear systems, concentrating now on thermal building.

Tayeb BENOUAZ. Born in Ain Sefra (Algeria), MSc in Tlemcen University (Algeria) (1984), PhD in Tlemcen University (1996). His current research interest includes the computational physics, modeling in physics and simulation of the nonlinear systems, stability of systems. Director several research projects and has several publications in this field.

Maamar HAMDANI. Born in Tiaret (Algeria), MSc in physics option: renewable energy from Tlemcen University (2011), researcher in Applied Research Unit on Renewable Energies "URAER Ghardaia”, research team: solar and bioclimatic architecture. He has many research papers in international and national journals/conferences. Currently he prepares PhD degree, and he concentrates his studies on developing an adaptive model of thermal comfort in reacting on the orientation, thermal insulation and building materials. He has published many articles in national and international journals.

Mohamed Kamel CHERIER. Born in Tiaret (Algeria), MSc in physics option: renewable energy from Tlemcen University (2010), researcher in Applied Research Unit on Renewable Energies "URAER Ghardaia”, research team: solar and bioclimatic architecture. $\mathrm{He}$ is interested in several areas, such as: thermal standards in buildings, passive and active solar architecture, and adaptive thermal comfort. He has published a number of papers in international journals and conference proceedings dealing with thermal building.

Mohamed Rédha YAICHE. Chief Engineer in the Development Center of Renewable Energies, CDER Bouzaréah (Algiers-Algeria), and his present research activities are in the area of the potential solar in Algeria. He is interested in the influence of various radiometric parameters on solar systems performance for different types of sky. Many codes have been conceived and developed in the EXCEL language to adopt several theoretical approaches. These computer codes are the most complete range for creating conversational interfaces. It reduces the execution time, and allows users to better understand the information and react quickly. He has about 25 years of research experience and he has published many related articles in this field.

Noceir BENAMRANE. Engineer in architecture from University of Constantine, he works in scientific research as assistant researcher in renewable energy domain; member in several projects in Applied Research Unit on Renewable Energies "URAER Ghardaïa", research team: solar and bioclimatic architecture. He is interested in 2D and 3D architectural design using modelling software such as l'AUTOCAD, MAXON cinema 4D and Autodesk Ecotect for the design and bioclimatic study. 